\title{
"Ce n'est pas Politique » - An Anthropological Approach of the Cognitive Relation Media/Politic
}

\author{
Irena Myzeqari, PhD. Cand \\ Department of Public Relation- Communication, \\ European University of Tirana, \\ Irena.myzeqari@uet.edu.al
}

Aleksander Dhima, Prof.Dr.

Department of Political Sciences and International relations,

European University of Tirana,

Aleksander.dhima@uet.edu.al

\begin{abstract}
This article is part of a research project conducted by Prof.Dr. Aleksander Dhima, senior researcher and PhD candidate Irena Myzeqari, who are working together on behalf of the scientific projects organized and funded by the European university of Tirana. The aim of this project is to put light on some aspect of the medial reality in Albania regarding the sphere of public information, the political communication and with the absent democratic culture of transmitting this information. In this study are treated some theoretical and practical issues that are related with main features and elements of the political communication and with the handicap of communitarian communication that is completely absent in the Albanian cultural reality. Through a detailed anthropological analysis of actual performance of the political actors, this study tries to find some knots between their cultural "model" and the so called transparent "regime" of the political messages, especially during the electoral campaign. Based on a detailed analysis of the cultural indicators that cause the problematic actual co-dependence between media and politics in this country, this study aims to reassess whether is any real chances for an effective change in the field of collaboration between media and politics, and if so, which would be some of the possible mechanisms that would make this change possible. The impact of the findings, could serve as a methodological basis for answering why we have this state of collaboration between these two actors, an answer that could lead to other vectors of investigation in the future. In the study become clear the principal medial elements, that have influenced the political communication in the Albanian reality such as the fragility of the democratic process during transition; the centralizing motivation for public (non) engagement in decision making; limited freedom of thought and speech especially when referring to opinions articulated by scientific voices on political behaviour and ethics, as indicators conditioned by culture and other traditional factors of the social structure. Thanks to works conducted on the Albanian tradition, in the study are identified primary resources that generate authoritarian effects and negative consequences on these indicators.
\end{abstract}

Keywords: media, politics, cognitive schemes, tribal organizations, political communication

\section{Introduction}

In the multiplicity of issues and problematic of anthropology of communication, one of the main actual themes is the relationship "media-politics", which is generally treated within the framework of cognitive aspects of human experience. Main points of reference regarding this issue are related with some methodological aspects such as cognitive organization and its influence in the way we experience different situations; the impact of media on politics; political transparency simulation from TV mediums etc.

The media is the main source of information regarding political issues and as such, it has complete control on what we know about the political system and on everything else that we cannot discover without its help. Said this, it becomes inevitable to think that media has more than "a certain impact" on the political sphere. That is why lately many researchers are in the opinion that media plays an important role on the way politics is done, especially in conditions of a noted conflict in the press and TV media, even though both of them "are happy" with their audiences. On the other side, media has tried 
to create a set of important standards for politics, spreading out the perceptions of the political world in the world of simple people and political leaders. It becomes extremely important during times of rapid political changes, such as elections, because media represents a specific method of knowing the world around; it surpasses the virtual barriers of information. Said this, media earns importance in everybody's social life, especially when it is seen as a mean of connection with politics. Media can judge, approve or criticize decisions taken by politics; it can sustain or interrupt political careers; the information it produces helps the audience to create their attitudes in relation with politics and how it reacts on different political situations or actors. That is why political parties have to seduce the media. Despite this, the audience in Albania has its own lenses to evaluate what media offers, influenced by their intellectual, cultural and social level. The anthropological analysis that the cultural orientation is against" and in fact it is only the top of the iceberg of the political attitude that the public performs. This state of facts has motivated us to study some of the phenomena of the today's Albanian medial reality in relation with the cognitive nature of politics, through a documented research on causes, consequences and on possibilities of introducing new cultural values on this field of research.

\section{Objectives, methodology and main research questions}

As we mentioned above, this paper is part of a larger project on media and politics. Said this, it is important to mention some of the main objectives and research questions posed in the whole research and of course the specific purposes of this paper. The main parts of the project have to do with: 1- the impact of cultural democracy in media's functionality; 2- the analysis of the media programs (audiovisual, printed and electronic version) in transmitting the political meaning in Albania in a 20 year period, from 1991 till 2013; 3- the dimensions/ stages of medial transformation; 4- Cultural "lenses" of the Albanian audience; 5 - the handicap of the public and communitarian communication in relation with the "against" cultural orientation and last 6- the public ethics in the Albanian media. The project has two main objectives. Firstly, it aims to verify the role of the media in the process of a constructive political communication in creating a new reality in the Albanian society. Secondly, it wants to emphasize main elements that have influenced the cultural aspects of the political communication during transition, which create long term consequences in modifying the political orientation. The methodology of the entire research is a mixture of quantitative and qualitative methods; in the first part of the analysis we will deal with data taken by different mediums( written or visual in a 20 years period), while in the second part we will discuss the results taken by 60 questionnaires collected online, by a sample chosen randomly. The questionnaire was semi- structured and the age sample varies from 18 up to 25 years old, following their undergraduate or graduate studies. At the end the methodology is interpretative in the sense that the reflected reality is social and not necessarily positivist. In this paper we will try to give an answer to two main questions. Firstly, are there any real chances for an effective change in the cognitive collaboration between media and politics in Albania and who might be the possible mechanisms to guarantee such change? Secondly, why the political communication is more seen as culture and citizenship than as an offence and avoidance from the truth and responsibility? Thirdly, what kind of perceptions share the youth about the influences that media plays in their political attitudes? Last but not least can we objectify the scale of influence that media has on the poor cultural and democratic behaviours of the political elite.

\section{Theoretical Framework}

The cognitive organization of political situations has a direct relationship with the ways people (Albanians in our case) perceive the political message and how is this personal/ communitarian perception modified. The new trends in cognitive anthropology aim to study the way in which "the schemes" created in people's mind are related with human interaction, an aim that obliges us to evaluate in a new approach emotions and motivations in the process of internalizing the political message ( Romney, 2002; pp. 14607),. The political communication in Albania has created a contradictory situation that has faded the primary difference between "the truth" and "the lie", when anthropologically it was expected the contrary; that the truth would be attested through norms and new values of a functional democracy. The citizens of this country are tired from this extreme relativism that has numbed their political actions and their hope for a democratic future (Fuga, 2008; pp.20)

The transformation of media during these years cannot be divided from the other cultural, political and social developments that the country has been subjected to, but in a broader sense, far from democratic revolutions;(Habermas 1989; pp.3031); copying and imitating the western trends of mediums was and still is perceived as generative source, but without having a clear and inner reflection for the innovations and the defect of this model. Albanian, even today, is captured in the chains 
of a tribal form of organization and this primitive "communitarian homogeny" above all means a higher scale of life security (Dhima, 2013; pp.328). The audience experiences "thinking differently" in total silence, as a stage of numbing the "contrary "attitude that is more present when the public is under pressure. Silence is a result of the dictatorial experience that this country has had, which is still a social complex, primarily caused by the behaviour of the political parties and their leaders or representatives.

The Albanian community has strong feature of a familiar structure and less of territoriality (neighbourhood/ village/ town/ city). From previous empirical studies results that "the word- mouth" is an important cultural instrument in more than $82 \%$ of the population in contrast with other instruments or communicative channels. However, this "capacity" has not motivated any political organization in Albania to start working with processes of capillary communication (Fleicher 2003; pp.371) This is a testimony of the general negligence that you can feel in the national environment in relation with the public communication and a kind of refusal to be involved in decision making processes. Since the communist period, but surely even earlier, the Albanian public has adopted double standard behaviour; they have one reality for public appearance and another one for personal/ familiar consume. Denouncing a negative phenomenon in media happens only when it has a direct influence for the one who accuses. On the contrary, when the injustice happens to a third member, it does not produce or attracts public attention because it is peripheral news. Collective denounce happens only under strict orientations, leaded by the highest communitarian hierarchy.

\section{Media power}

In the modern world, media power is inevitable and very important for human society and the modern man who has the need to receive information, fast and in real time. Media becomes important, especially in times of political violence and wars and that is why political leaders try to keep under controll media coverage during these times. This power is increasing day by day thanks to technology development and this power, even though its called the fourth power, influeces other types of power as well, playing an important role in decision making. Different mediums have a codependent relation with politics, but they have evolved more rapidly, because they were more capable in defending the public interests. It knows how to create contacts, earn people's trust and entertain they, what seems unthinkable for politics.

Media fulfills three main functions:

1- It guarantees freedom of speech or better to say that oblige politicians to be faced with the public opinion sentence

2- Keep the community united, giving to citizens common references at the same time

3- Make possible a coordinated action, because people and parties generally do not speak face to face, only during campaigns.

Individuals feel closer among them, because of the need to support common opinions and the press makes possible the creation of this experience. Refeerring to Artan Fuga( 2010), who says that... ' media studies of a specific time, is a method or a gate towards the society ( $p p .10)$, we could evaluate the role of the media in the process of constucting political communication and creating a new social reality. Said this, we can easily understand now the changes that political communication has suffered especially in terms of attitude and language use. Media is an epistemological method of knowing the world around us, a method to surpass virtual frontiers of information and as such it becomes quite important in the each individual social life, especially when its is perceived a connecting mean of doing politics.

\section{Political Communication}

Political communication includes each type of communication that has as an object politics and it has two main features: the enlargement of the political sphere and the increase of the role of communication in everyday life. It does not only "diminish" political antagonisms through direct debate, but it gives a broader sense to democracy as well. This happens because politics is gaining more and more a public character, thanks to different mediums; politics becomes real, not only through human personal experience, but through its medial appearance as well. An important ingredient of this process is the reflective communication that aims to create political convictions in the audience that later on would become political decisions or behaviours. Aleksander Dhima says that during this kind of communication we can catch technical and semantic dimensions of the political message and signals taken by the social context (Dhima, 2010, pp: 10). 
Communication in politics is mainly reflective because it is related with elaborated messages that have to do with the cognitive organization of the ethno cultural "cut" of different target groups.

Political communication has created a contradictory situation in Albania that has faded out the difference between the truth and the lie, when anthropologically it was supposed to be the contrary; that the truth should have been attested through norms and new values of a functional democracy.

Politics media coverage is in crisis, because political communication is in its essence exclusive; it is based in power techniques. This can happen also because the increased number of communicative channels that deform somehow the political communication and bring in front of the audience political elite that lacks a strong ideological axe. That is why the media attempt to be neutral is still questionable. The new political elite in Albania has many deficiencies in knowing basic principles of maintaining a functional legal state and democracy. Media shows a low democratic level and a lack of vision and functional and effective approaches. 20 years later we cannot justify any longer the absence of this democratic culture.

The media co-dependency is quite important when we analyse the political communication among actors and some of the main effects of media on political communication are: selective memory; communicative climax; personal though and personification of each political activity

They become extremely important in times of rapid political changes, such as elections. That is why political leaders try to maintain under control everything that happens during these periods. All media coverage influences the public opinion, much more that informal and closed doors meetings. Candidates use media to attract more attention and elections in general are affected by two main factors: by the force and the political image of the candidate and the way media interprets his/ her performance.

\section{Political communication in the Albanian cultural reality}

When we speak about this topic, we should keep in mind at least these three elements. Firstly, the democratic process in Albania started in a period of total lack of dissidence, where people for 50 years were used only with the so called "popular democracy", where in text books nobody spoke about pluralism and where the topic of freedom and human rights was prohibited and where people who worked in the highest hierarchy did not have a broad vision and culture on western democracy.

In these circumstances took life the process of democratisation, a process that required a new elite and a new leadership and even though they were created, their form was abstract and they were lacking standarts and political concepts to create a solid democracy.

Secondly, democracy is all about communication and collaboration. In this context, political communication has its special role and people often think that it is easy to do politics and forget that political communication is more about the dialogue and less for monologue, is more about listening and inclusion and less about punishment and centralizing tightening, is more about the truth and citizenship. Thirdly, the political behaviour here is fixed and regulated based on personal approaches of the leaders and less based on ideologies of political inclusion of the community. The research conducted in this field identify three main sources that influence and have long terms effects on political behaviour and they are family, the authority and the social circle, all three that could influence the political orientation. 'Friendships have the advantage of being in the same generation that somehow shares the same cultural mentality, norms and values that are experienced and developed together in the community'(H.R. Kitayama \& S. Markus, pp. 277-283). We can add some other elements to the previous ones that have to do with the scale and the efficiencies of media appearance and individual choices about political parties. Even though their short term actions, they have a long term effect on political orientation in specific moments. Many researchers believe that massmedia plays an important role in the electoral environment and it has been a decisive factor in liberal democracies.

Since the fall of communism, in 1991 -1992, the transition from a centralized economy to a free market brought major social and political changes. This period was a continuous attempt to establish a democratic regime, part of which was also the development of communication means and this moment signs a new reality in the communication, which was quite different from what happened during communism.

In the post communist Albania, the first language of communication that media delivered was freedom of expression, a language that was chosen to be part of the political communication through the slogan "freedom and democracy". Artan Fuga says that the news feed up a long absence, offering a new dimension to the individuals, far from forced collectivism, 
and giving life to a strong desire to receive any kind of information (Fuga, 2010: pp.22). Naturally, this role and function of media was strengthened with the opening of many more journals, newspapers and private licences, who, through, their editorials, language and rhetoric, brought a new era of communication and 'in a variety of features, the most special one was to teach and learn a new political language' (Glukmani, 2010; pp. 219)

\section{Results and analysis}

As it was mentioned above, the applied methodology to collect data for this project and especially for this paper was quantitative. In the first stage of it, were completed 60 questionnaires that were spread online. The target were youth of an age rate from 18 up to 25 , aiming to capture youth that had voted at least one time or mostly 3 times in their lives, local and general elections. The majority of the people who were part of the sample were following their university studies, round $65 \%$, while $27 \%$ were following postgraduate studies. Only $8 \%$ of them had just finished high school and were not registered in any university. We tried to respect a gender balance among the respondents and at the end resulted that $55 \%$ of the sample were female and $45 \%$ were male.

The questionnaire had 14 questions, 13 were closed questions and the last one opened. It persisted in three main pillars. Firstly we wanted to understand how important was the political information for the youth and how much were they prone to search and look for this kind of information. Secondly, we tried to discover who were the principal sources of information from which they received information and last but not least we tried to capture their perceptions about the role that media plays, especially those chosen by them, in their political education in relation to other educative "structures". The answers are grouped in four parts, and each of them fulfils one the objectives mentioned in the beginning.

To the question, how much is it important the political information for the youngsters, the majority of them, round $45 \%$ believe that the political information is averagely important for them, $35 \%$ are on the opinion that it is not that important while $20 \%$ admit that it is not important at all. The other question asked them "who were the main sources of information they used when referring to political information". The answers show that youth have a clear tendency towards the television, which is classified as the main source of information. The press and the official pages of political parties achieve non considerate percentages, while the option radio" was not chosen by anyone.

When talking about the Television, the sample makes a list starting from the most reliable channel till the least reliable for them. The first television was Top Channel, who has an audience of more than $80 \%$ of the sample, while other televisions such as Klan or Vizion plus take very small percentages. In this point of the questionnaire they were also asked about the importance of online political communication that was an innovation for the last general elections. They see it as a new tendency of doing politics and we notice a trend of balance between those who embrace this new alternative channel of communication with those who completely negate dealing with that.

Youth sound to be quite worried about the level of propaganda and demagogy that the Albanian Medias serve to them. Round $75 \%$ of the sample admit that the information they receive is in most of the cases pure propaganda in favour of one or the other party and that the level of debate that they offer has neither content nor messages and as a consequence they put less and less trust in these media. They think that this kind of information offered by them numbs their capacities of political activism.

The last question was an open question, because we wanted to collect people's thoughts and opinions on this statement "Media does not tell us how to think, but it defines what we should think about". Is adaptable for the Albanian reality? We conducted a content analysis to the answers we received and at the end it was concluded that it is our reality that give total freedom to the media to take this role and to decide on what we think and how we think about a specific matter. Said this, its effects on the cognitive schemes of youth is quite high, and as it looks like, quite negative because related with the concept of civil engagement that was quite problematic for this target group, it seems that media is somehow guilty for the passive attitude that youth have towards politics and the political information.

For illustration below is written a short review of the opinions we collected.

"Media is the mirror of our society; through its reflections we see (the fairest and the nearest stories that happen round us). The closest they are the harder is for us to judge on these issues. Media helps us to help and gives us the tool on how to think for each of this stories or events. I think, i reflect, i react when media transmits me a story where i can have a say, but does a voice change the entire society instead of three million? 
At the end we can conclude that the transformation and changes that the media has been subjected to cannot be seen and studied dividedly from the other cultural, political and social developments of the Albanian society. From the overall responses results that:

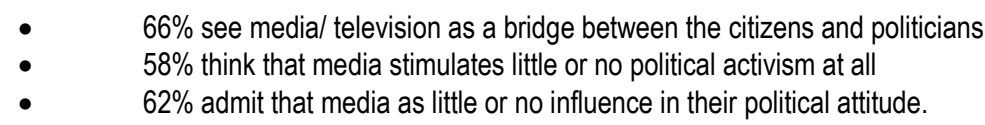

\section{Conclusions}

The focus of this project was political communication that occupies the biggest amount of time in news and in media discourse, because the individuals feel closer when they share common opinions and the media (especially the press) does not create this feeling to the audience. It is media's fault for the diversity of opinions and the power that it possesses could make possible that some opinions would "triumph" easier than others and imply a broader consensus among the audiences.

Secondly, knowing that media in Albania has evolved more rapidly compared to politics, due to its capacity to create multidimensional contacts with people and to spread information in all times, it deserves to have a bigger power in defending the public interests. But the reality shows that media has used this power for bad purposes.

Thirdly, media- despite its importance- has bad effects on politics as well. It can judge, approve, or criticize the decisions taken by politicians. The information that media produces baffles the audience and influence their critical attitudes towards politics. The world history is full of examples where media has been the primary cause of a ruined political career.

At the end, till this stage of research, we can highlight some main medial elements that have influenced the political communication in the Albanian reality. Some of these elements are:

a) Mentality ( difficult to be changed) that politics is the easiest exercised profession;

b) Centralized tightening for (non) public participation in decision making;

c) Obstacles in freedom of speech and thought and scientific arguments on behaviour and political ethics, as indicators conditioned by culture and other traditional factors of social structure

One of the main conclusions that we could draw is that the transformation of the Albanian media cannot be studied devided from other cultural, political and social developments, but in a broader sense, even from "democratic revolutions". As Habermas could say, imitating western Medias is a source of generation, but if it does not reflect inner changes, it will not function. Even today, Albanians suffer the consequences of a tribal organization that above all guarantees a higher scale of security for their lives. The audience experiences "thinking different in total silence, fading out any chance for a counter response. Silence has its source in the dictatorial experience of the country, which is still present as social complex, mainly because of the behaviour of political parties and their representatives.

\section{Limitations and further research}

This research paper contributes in the further awareness of the media institutions and the audience for the lack of transparency in transmitting the political message, due to the close relation media -politics and hidden interests of media owners and politicians. Some of the analyses conducted in this research create a qualitative debate and that many research centres do not possess. Said this, the results of this stage and of the upcoming one can be used by journalists, communication sciences, national and international agencies that deal with media problems and Albanian politics etc.

When we talk about limitations of the project, they are real and concrete for some essential reasons. Firstly, it is the first time that someone conducts a research on this topic and for this reason is impossible to make diachronic comparisons with previous records. Secondly, due to its specific requests, we cannot exclude subjectivity from the sample taken for the study. Last but not least, linguistics problems can be a cause for misinterpretations from other researchers or political makers, who are not that open when their work is criticized in scientific terms. As we said, in the beginning, the sample was a bit small, that is why the second stage of this project that starts in March, will focus on a larger number of interviews and target groups, from a variety of ages, educational level and origins, variables that would enrich the results of this project and increase its validity. 


\section{Bibliography}

[1] Fuga, Artan (2001). Ikja nga kompleksi i Rozafës. Pejë: Dukagjini.

[2] Id. (2005). Lexime në komunikim. Tiranë: Ora.

[3] Id. (2008a). Media, politika, shoqëria. Tiranë: Dudaj.

[4] Id. (2008b). Brirët e dhisë. Tiranë: Ora.

[5] Id. (2010a). Monolog; Mediat dhe propaganda totalitare. Tiranë: Dudaj.

[6] Id. (2010b). Pengesat në informimin publik. "Standard" 20 nëntor 2010.

[7] Habermas, Jürgen (1989). The Structural Transformation of the Public Sphere: An Inquiry into a Category of Bourgeois Society. Cambridge-MA: The MIT Press: 30-101.

[8] Id. (2006). The Public Sphere. Cambridge-MA: The MIT Press.

[9] Fleischer, C.S. (2003). Managing the Grassroots and Assessing its Performance. "Journal of Public Affairs" (New York City/ John Wiley and Sons Ltd) Vol. 3: 371-382.

[10] Kitayama, H.R. and S. Markus (2003). Culture, Self, and the Reality of the Social. "Psychological Inquiry" (Philadelphia-PA) Vol. 14, No. 3: 277-283.

[11] Gluckman, Max (1968). The Utility of the Equilibrium Model in the Study of Social Change. "American Anthropologists" (Hoboken-NJ) Vol. 70, No. 2: 219-237.

[12] Dhima, Aleksandër (2011). Modeli i propagandës: Qasje antropologjike në realitetin mediatik. "Polis" (Tiranë/

[13] UET) nr. 10: 23-37.

[14] Id. (2012a). Ekologjia humane dhe ndihmesa e shkollës së Çikagos në zhvillimin e antropologjisë sociale.

[15] "Polis" nr. 11: 181-191.

[16] Id. (2012b). Ndërveprimi konjitiv i medies me politikën. Konferenca „Sfidat mediatike të realitetit

[17] shoqëror shqiptar" (Tiranë/ UET, 10 maj 2012).

[18] Id. (2013a). Çfarë i mungon komunikimit politik në Shqipëri? Konferenca Kombëtare "Media, Komunikimi

[19] dhe Marketingu Politik; Në pritje të fushatës zgjedhore 2013" (Tiranë/ UET, 25 maj 2013).

[20] Id. (2013b). Globalizimi kulturor dhe komunikimi global. "Polis" nr. 12: 15-28.

[21] Id. (2013c). Antropologji e Komunikimit; Qasje në realitetin shqiptar. Tiranë: Kumi.

[22] Romney, Kimbell A. and Tarow Indow (2002). A Model for the Simultaneous Analysis of Reflectance. "Proceedings of the National Academy of Sciences of the United States of America" (Washington DC) Vol. 99: 14607-14610. 